\title{
Biochemical properties and evaluation of washing performance in commercial detergent compatibility of two collagenolytic serine peptidases secreted by Aspergillus fischeri and Penicillium citrinum
}

Érika Lika Ida, Ronivaldo Rodrigues da Silva, Tássio Brito de Oliveira, Tatiane Beltramini Souto, Juliana Abigail Leite, André Rodrigues \& Hamilton Cabral

To cite this article: Érika Lika Ida, Ronivaldo Rodrigues da Silva, Tássio Brito de Oliveira, Tatiane Beltramini Souto, Juliana Abigail Leite, André Rodrigues \& Hamilton Cabral (2017) Biochemical properties and evaluation of washing performance in commercial detergent compatibility of two collagenolytic serine peptidases secreted by Aspergillus fischeri and Penicillium citrinum, Preparative Biochemistry and Biotechnology, 47:3, 282-290, DOI: 10.1080/10826068.2016.1224247

To link to this article: https://doi.org/10.1080/10826068.2016.1224247

Accepted author version posted online: 23 Aug 2016. Published online: 10 Nov 2016.

山ll Article views: 77

View Crossmark data $\complement$ Submit your article to this journal $\llbracket$

ter

Citing articles: 5 View citing articles ¿ 


\title{
Biochemical properties and evaluation of washing performance in commercial detergent compatibility of two collagenolytic serine peptidases secreted by Aspergillus fischeri and Penicillium citrinum
}

\author{
Érika Lika Ida ${ }^{a}$, Ronivaldo Rodrigues da Silvab ${ }^{b}$ Tássio Brito de Oliveirac, Tatiane Beltramini Soutoa, Juliana Abigail Leite, \\ André Rodrigues ${ }^{c}$, and Hamilton Cabral ${ }^{a}$ \\ aDepartment of Pharmaceutical Sciences, School of Pharmaceutical Sciences of Ribeirao Preto, University of Sao Paulo, Ribeirao Preto, Brazil; \\ 'Department of Biology, Institute of Biosciences, Letters and Exact Sciences, Sao Paulo State University, UNESP/IBILCE, Sao Jose do Rio Preto, Brazil; \\ 'Department of Biochemistry and Microbiology, Sao Paulo State University, UNESP, Rio Claro, Brazil
}

ABSTRACT

Filamentous fungi secrete diverse peptidases with different biochemical properties, which is of considerable importance for application in various commercial sectors. In this study, we describe the isolation of two fungal species collected from the soil of decayed organic matter: Aspergillus fischeri and Penicillium citrinum. In a submerged bioprocess, we observed better peptidase production with the fungus $P$. citrinum, which reached a peak production at $168 \mathrm{~h}$ with $760 \mathrm{U} / \mathrm{mL}$, in comparison with the fungus $A$. fischeri, which reached a peak production at $72 \mathrm{~h}$ with $460 \mathrm{U} / \mathrm{mL}$. In both situations, the fermentative medium contained $0.5 \%$ crushed feathers as a source of nitrogen. On performing biochemical characterization, we detected two alkaline serine peptidases: The one secreted by $P$. citrinum had optimal activity at $\mathrm{pH} 7.0$ and at $45^{\circ} \mathrm{C}$, while the one secreted by $A$. fischeri had optimal activity in $\mathrm{pH}$ $6.5-8$ and at $55-60^{\circ} \mathrm{C}$. Metallic ions were effective in modulating these peptidases; in particular, $\mathrm{Cu}^{2+}$ promoted negative modulation of both peptidases. The peptidases were stable and functional under conditions of nonionic surfactants, temperatures up to $45^{\circ} \mathrm{C}$ for $1 \mathrm{~h}$, and incubation over a wide $\mathrm{pH}$ range. In addition, it was observed that both peptidases had the capacity to hydrolyze collagen and performed well in removing an egg protein stain when supplemented into a commercial powder detergent; this was especially true for the peptidase from $P$. citrinum.

\section{KEYWORDS}

Biochemical

characterization; crude enzyme extract; protease application; proteases; submerged fermentation

\section{Introduction}

Microorganisms have been used in the production of several metabolites for a long time. Certain characteristics, including their biochemical diversity, facility of growth, adaptation to different environments, and potential for genetic manipulation, make these organisms interesting sources for enzyme production. ${ }^{[1]}$

In submerged fermentation, varying the composition of the culture medium directly affects the level and diversity of enzyme expression. In this context, filamentous fungi exhibit a great capacity for the secretion of hydrolytic enzymes and this production depends on growth conditions such as temperature, $\mathrm{pH}$, carbon and nitrogen sources, and time of incubation. ${ }^{[2]}$

Peptidases can be produced by microorganisms, and they are important enzymes with applications in many industrial sectors, such as the production of cheese, meat, fish, and wine; protein hydrolysates; the pharmaceutical industry; the leather industry; cosmetics; and fine chemicals. In addition, peptidases are important additives in detergent formulation to remove protein stains such as those from blood, egg, and food debris. $^{[3,4]}$

The use of peptidases in various industrial sectors is in a continuous process of growth; biotechnology and basic research in this field are in line with new research on the production and application of these enzymes. Thus, in this study, we propose to evaluate peptidase production using a submerged fermentation bioprocess to characterize the peptidases biochemically and to evaluate the washing performance of these enzymes supplemented into commercial detergent. The collagenolytic activity and the feasibility in supplementation of these peptidases into a commercial detergent to remove an egg protein stain are demonstrated in this study.

\section{Experimental}

\section{Isolation and selection of fungal strains}

The fungi were isolated from decaying wood found in soil. The fungal strains were selected based on their ability to produce and secrete peptidases. Experiments were performed in petri dishes with a selective medium containing $\mathrm{KH}_{2} \mathrm{PO}_{4}(0.7 \%)$; $\mathrm{K}_{2} \mathrm{HPO}_{4}(0.2 \%) ; \mathrm{MgSO}_{4} \cdot 7 \mathrm{H}_{2} \mathrm{O}(0.01 \%)$; yeast extract $(0.1 \%)$; casein $(0.3 \%)$; and agar (1.5\%). Culture medium was autoclaved at $121^{\circ} \mathrm{C}$ for $15 \mathrm{~min}^{[5]}$ The fungi were spread onto the solid agar and incubated at 30 or $40^{\circ} \mathrm{C}$, for a period of approximately, 24-168 h.

To select the best fungal strains for peptidase secretion, the fungi were spread in potato-dextrose agar (PDA) slants and incubated at $30^{\circ} \mathrm{C}$ (Penicillium citrinum) and $40^{\circ} \mathrm{C}($ Aspergillus 
fischeri) for $168 \mathrm{~h}$ to allow for complete growth. Stock cultures were maintained at $4^{\circ} \mathrm{C}$.

\section{Fungal identification}

Preliminary analyses identified fungal strains using the morphological characteristics and microscopic reproductive structures of the colonies. Such morphological markers were used to identify all isolates up to the genus level. After morphotyping, all fungal strains were further identified using molecular markers. DNA extraction, quantification, and sequencing were performed following the protocols described in Arcuri et al. ${ }^{[6]}$ The strains were sequenced using primer pairs determined to be the best markers for defining a particular species: $\beta \mathrm{t} 2 \mathrm{a}$ and $\beta \mathrm{t} 2 \mathrm{~b}$ for the $\beta$-tubulin gene. ${ }^{[7]}$

Forward and reverse sequences were assembled in contigs using BioEdit v.7.1.3. ${ }^{[8]}$ Contigs were used to query for homologous sequences in the NCBI GenBank database using the BLASTn tool (http://blast.ncbi.nlm.nih.gov/). After taxonomic affiliation, we retrieved sequences of reference strains (mostly derived from the CBS-KNAW Fungal Biodiversity Centre) for phylogenetic analysis. The alignment was built using MAFFT v. $7158 .{ }^{[9]}$ The phylogenetic tree was inferred with MEGA v.5.05 ${ }^{[10]}$ using the neighbor-joining algorithm under Kimura 2 parameters as the substitution model, and gaps were excluded from the analysis. For branch support, we calculated 1,000 bootstrap pseudo-replicates.

\section{Submerged bioprocess}

The effect of culture medium composition in the production of peptidases was examined. To 250-mL Erlenmeyer flasks, $50 \mathrm{~mL}$ of culture medium containing the following was added: $\mathrm{KH}_{2} \mathrm{PO}_{4}(0.7 \%), \mathrm{K}_{2} \mathrm{HPO}_{4}(0.2 \%), \mathrm{MgSO}_{4} \cdot 7 \mathrm{H}_{2} \mathrm{O}$ (0.01\%), citrate $2 \mathrm{H}_{2} \mathrm{O}(0.01 \%)$, yeast extract $(0.1 \%)$, and $\mathrm{CaCl}_{2} \cdot 2 \mathrm{H}_{2} \mathrm{O}$ $(0.01 \%)$. The fermentative medium was autoclaved at $121^{\circ} \mathrm{C}$ for $15 \mathrm{~min}^{[11]}$

The medium was inoculated with fungal spores resuspended in sterile distilled water in an aseptic area $\left(5 \times 10^{5}\right.$ spores $/ \mathrm{mL}$ ). The fermentative bioprocess was conducted from 24 to $168 \mathrm{~h}$ at $120 \mathrm{rpm}$; every $24 \mathrm{~h}$, one Erlenmeyer flask was removed, and the material was vacuum filtered using Whatman filter paper No. 1. The filtrate was used as a crude enzymatic solution to quantify proteolytic activity.

To determine the effect of culture medium composition for optimal peptidase production, studies were conducted by varying nitrogen sources (peptone, casein, and crushed feather, all at a concentration of $0.5 \%)$, time $(24-168 \mathrm{~h}$ ), and the same concentration of the inoculum, and initial $\mathrm{pH}$ of the medium.

\section{Proteolytic activity assay}

The effects of different parameters evaluated in the fermentation bioprocess were determined on the basis of proteolytic activity. The assay of proteolytic activity was assessed according to the protocol described by Sarath et al. ${ }^{[12]}$ with some modifications.

Evaluation of the profile of peptidase production was performed using a caseinolytic assay. For determination of proteolytic activity, we used a reaction mixture consisting of $100 \mu \mathrm{L}$ of enzymatic extract, $100 \mu \mathrm{L}$ of monobasic sodium phosphate buffer $(0.05 \mathrm{M}, \mathrm{pH} 6.5)$, and $1000 \mu \mathrm{L}$ of $1 \%$ casein solution. The reaction was performed for $60 \mathrm{~min}$ at $40^{\circ} \mathrm{C}$. After the incubation, the enzymatic reaction was stopped with the addition of $600 \mu \mathrm{L}$ of $10 \%$ trichloroacetic acid (TCA), ${ }^{[5]}$ and the mixture was centrifuged for $10 \mathrm{~min}$ at $10,000 \mathrm{~g}$ at $25^{\circ} \mathrm{C}$. The proteolytic activity of the supernatants was measured using a spectrophotometer at $280 \mathrm{~nm}$ against blank controls. Caseinolytic activity unit (A.U.) was defined as the amount of enzyme required to promote the release of $1 \mu \mathrm{mol}$ of tyrosine/min under defined test conditions. ${ }^{[13]}$

Functional biochemical characterization was performed using azocasein as a substrate, according to the protocol described by Ducros et al. ${ }^{[14]}$ The reaction mixture consisted of $100 \mu \mathrm{L}$ of enzymatic extract, $100 \mu \mathrm{L}$ of the appropriate buffer $(0.05 \mathrm{M})$, and $200 \mu \mathrm{L}$ of $1 \%$ azocasein. The reaction was performed for $30 \mathrm{~min}$ at different temperatures and stopped by adding $800 \mu \mathrm{L}$ of $10 \%$ TCA. Reaction and blank control tubes were centrifuged at $10,000 \mathrm{~g}$ for $10 \mathrm{~min}$ at $25^{\circ} \mathrm{C}$, and $800 \mu \mathrm{L}$ of the supernatant was added to $933 \mu \mathrm{L}$ of $1 \mathrm{M} \mathrm{NaOH}$ in a separate test tube. The absorbance of this mixture was measured in a spectrophotometer at $440 \mathrm{~nm}$ against each respective blank control.

Collagenase activity was performed according to the protocol described by Mukherjee et al. ${ }^{[15]}$ The reaction mixture consisted of $50 \mu \mathrm{L}$ of enzymatic extract and $500 \mu \mathrm{L}$ of $1 \%$ Azocoll dissolved in monobasic sodium phosphate buffer ( $0.05 \mathrm{M}, \mathrm{pH}$ 6.5). The reaction was stopped by immersing the tubes in ice for $5 \mathrm{~min}$. For blank control tubes, the enzyme was primarily inactivated by incubation at $100^{\circ} \mathrm{C}$ for 20 min. Hydrolysis of Azocoll was evaluated by measuring the absorbance at $520 \mathrm{~nm}$ in a spectrophotometer. One unit of azocollagenolytic activity was defined as the amount of enzyme required to increase the absorbance reading at $520 \mathrm{~nm}$ by 0.1 in $1 \mathrm{~h}^{[16]}$

\section{Biochemical characterization}

Biochemical characterization of the peptidases was performed using a $1 \%$ azocasein substrate. The effect of $\mathrm{pH}$ on enzymatic activity and stability was evaluated using buffer salts (Good Buffer) between $\mathrm{pH} 4.5$ and 10.5 at intervals of 0.5 units.

The effect of temperature on the activity and stability of enzymes was studied using a buffer of predetermined optimal $\mathrm{pH}$, over a range of temperatures from 30 to $70^{\circ} \mathrm{C}$ at intervals of $5^{\circ} \mathrm{C}$. The effect of metal ions was also studied $\left(\mathrm{Li}^{+}, \mathrm{Na}^{+}, \mathrm{K}^{+}\right.$, $\mathrm{Ba}^{2+}, \mathrm{Ca}^{2+}, \mathrm{Mg}^{2+}, \mathrm{Mn}^{2+}, \mathrm{Fe}^{2+}, \mathrm{Ni}^{2+}, \mathrm{Cu}^{2+}, \mathrm{Co}^{2+}, \mathrm{Al}^{3+}$, and $\mathrm{Zn}^{2+}$ ). Each ion had a final concentration of $5 \mathrm{mM}$.

Enzyme subclasses were also determined based on their proteolytic activity in the presence of inhibitors: iodoacetic acid (IAA), ethylenediaminetetraacetic acid (EDTA), and phenylmethanesulfonyl fluoride (PMSF). Each inhibitor had a final concentration of $5 \mathrm{mM}$. All assays were performed in triplicate using the optimal reaction conditions with respect to $\mathrm{pH}$ and temperature.

We also evaluated the effect of ionic (SDS and CTAB) and nonionic (Tween 20 and Triton X-100) surfactants on proteolytic activity at the following concentrations: $0.1,0.2,0.5$, and 
$1 \%$. All assays were performed in triplicate using the optimal reaction conditions with respect to $\mathrm{pH}$ and temperature.

\section{Washing performance of peptidases supplemented in commercial detergent}

We spotted white cotton fabric (size, $2 \times 2 \mathrm{~cm}^{2}$ ) with $25 \mu \mathrm{L}$ of homogenized egg. The cotton fabrics were maintained at $25^{\circ} \mathrm{C}$ until the stains dried.

To prepare a commercial powder detergent for supplementation with extracted enzymes, it was autoclaved at $121^{\circ} \mathrm{C}$ for $40 \mathrm{~min}$ to completely denature the enzymes present in the commercial formulation. An enzymatic assay was performed to confirm the lack of proteolysis.

The commercial detergent with denatured enzymes was then supplemented with crude enzymatic extract from $P$. citrinum and A. fischeri to obtain the same proteolytic activity as that present in the commercial detergent (1 A.U./mL of washing mixture). The proteolytic activity of the commercial powder detergent was defined using a caseinolytic assay ( $1 \%$ casein) in monobasic sodium phosphate buffer $(0.05 \mathrm{M}$, $\mathrm{pH} 6.5$ ) at $40^{\circ} \mathrm{C}$. Using equivalent concentrations of enzymes in the washing assay, it is possible to compare the washing performance of commercial detergent and that of the detergent supplemented with our enzymes.

Washing experiments were performed in falcon flasks $(50 \mathrm{~mL})$ containing $25 \mathrm{~mL}$ of washing mixture (aqueous solution + detergent + enzyme + spotted cotton) and agitated at $120 \mathrm{rpm}$ in a shaker for $30 \mathrm{~min}$ at $30^{\circ} \mathrm{C}$. After that, the cotton fabric was rinsed and maintained at $45^{\circ} \mathrm{C}$ until it was dry. Washing experiments were also performed using commercial detergent (with denatured enzyme), active commercial detergent, and water under the same test conditions.

\section{Statistical analyses}

Statistical analyses were performed with GraphPad Prism version 5.0 software using ANOVA. Differences were considered significant at $p<0.05$.

\section{Results and discussion}

\section{Isolation, selection, and strain identification}

Soil samples were inoculated in petri plates containing PDA medium. Replicate plates were incubated at 30 and $40^{\circ} \mathrm{C}$ for $168 \mathrm{~h}$. After growth, fungi were subcultured, from which 12 fungal strains were isolated. These 12 fungal strains were plated in selective medium as described above to check for the secretion of peptidases. From the 12 morphotypes, two fungal strains (F7 and F8) were isolated that showed good peptidase production, indicated by the presence of a halo around the mycelium (data not shown). After sequencing the $\beta$-tubulin gene of strains F7 and F8, BLAST results indicated that the closest relatives to these strains were A. fischeri (also known as Neosartorya spinosa) KACC 41647 (accession \#: AY870760) at $100 \%$ similarity and P. citrinum (accession \#: KJ413333) at $99 \%$ similarity. Subsequently, phylogenetic analysis was performed, demonstrating the taxonomic affiliation of the F8 (Figure 1a) and F7 (Figure 1b) strains.

\section{Peptidase production profile in the submerged bioprocess}

Preliminary studies in petri plates with PDA media showed that the best temperature for growth of $P$. citrinum and A. fischeri was 30 and $40^{\circ} \mathrm{C}$, respectively (data not shown).

Enzymatic reaction profiles of peptidase production were evaluated over a period of 24-168 h. In submerged bioprocess $(\mathrm{SmB})$ with $P$. citrinum, media supplemented with $0.5 \%$ crushed feathers reached the highest peptidase production in $168 \mathrm{~h}$ with $780 \mathrm{U} / \mathrm{mL}$ (Figure 2a). Media supplemented with casein or peptone, both of which were used at $0.5 \%$, reached the next highest level of peptidase production, at 303 and $216 \mathrm{U} / \mathrm{mL}$, respectively. These results highlight the importance of these sources for the production of peptidases since fungi cultured in medium deprived of such components (i.e., standard medium) produced low amounts of these enzymes.

Aspergillus fischeri demonstrated peak peptidase production at $72 \mathrm{~h}$ with $420 \mathrm{U} / \mathrm{mL}$ in fermentative medium containing $0.5 \%$ crushed feathers (Figure $2 \mathrm{~b}$ ). In medium supplemented with $0.5 \%$ casein, $A$. fischeri exhibited the best production at 96 h with $97.7 \mathrm{U} / \mathrm{mL}$.

Aspergillus and Penicillium are fungal genera with recognized capacity for peptidase secretion. ${ }^{[5,17]}$ Comparatively, it is notable that peptidase production by $P$. citrinum was approximately twofold higher than that of A. fischeri. Animal residues, specifically crushed feathers, enhance peptidase production; use of such products in fermentative bioprocesses may decrease the cost of production and possibly add economic value to animal wastes.

Moreover, it was interesting to note the ability of crushed feathers, a complex substrate, to enhance peptidase production in this study. Similar results in studies by Pandey ${ }^{[18]}$ and Silva et al. ${ }^{[5]}$ also reported that complex substrates (e.g., wheat bran) were better inducers of peptidase secretion than synthetic proteins like casein and peptone in filamentous fungi.

\section{Effect of $\mathrm{pH}$ and temperature on the activity and stability of peptidases}

In Figure 3a, we noted optimal activity over $\mathrm{pH} 6.5-8$ for A. fischeri, although this did not reach statistical significance ( $p=0.49$ ), and an optimum activity at $\mathrm{pH} 7.0$ for P. citrinum. Another activity peak at $\mathrm{pH} 8.5$ (for P. citrinum) and $\mathrm{pH} 9$ (for A. fischeri) may be explained by the possible presence of more than one peptidase in both crude extracts; slight $\mathrm{pH}$ variations are known to influence different peptidases under different reaction conditions. In addition, a progressive loss of proteolytic activity occurred at higher $\mathrm{pH}$ values. For example, enzyme activity decreased by $50 \%$ at $\mathrm{pH} 8.5$ for the enzymatic extract from $A$. fischeri and approximately $60 \%$ for the enzymatic extract from $P$. citrinum at $\mathrm{pH} 8$.

The ability to secrete alkaline peptidases by various species from Aspergillus and Penicillium has been described, for example, studies by Tunga et al. ${ }^{[19]}$ on Aspergillus parasiticus, 


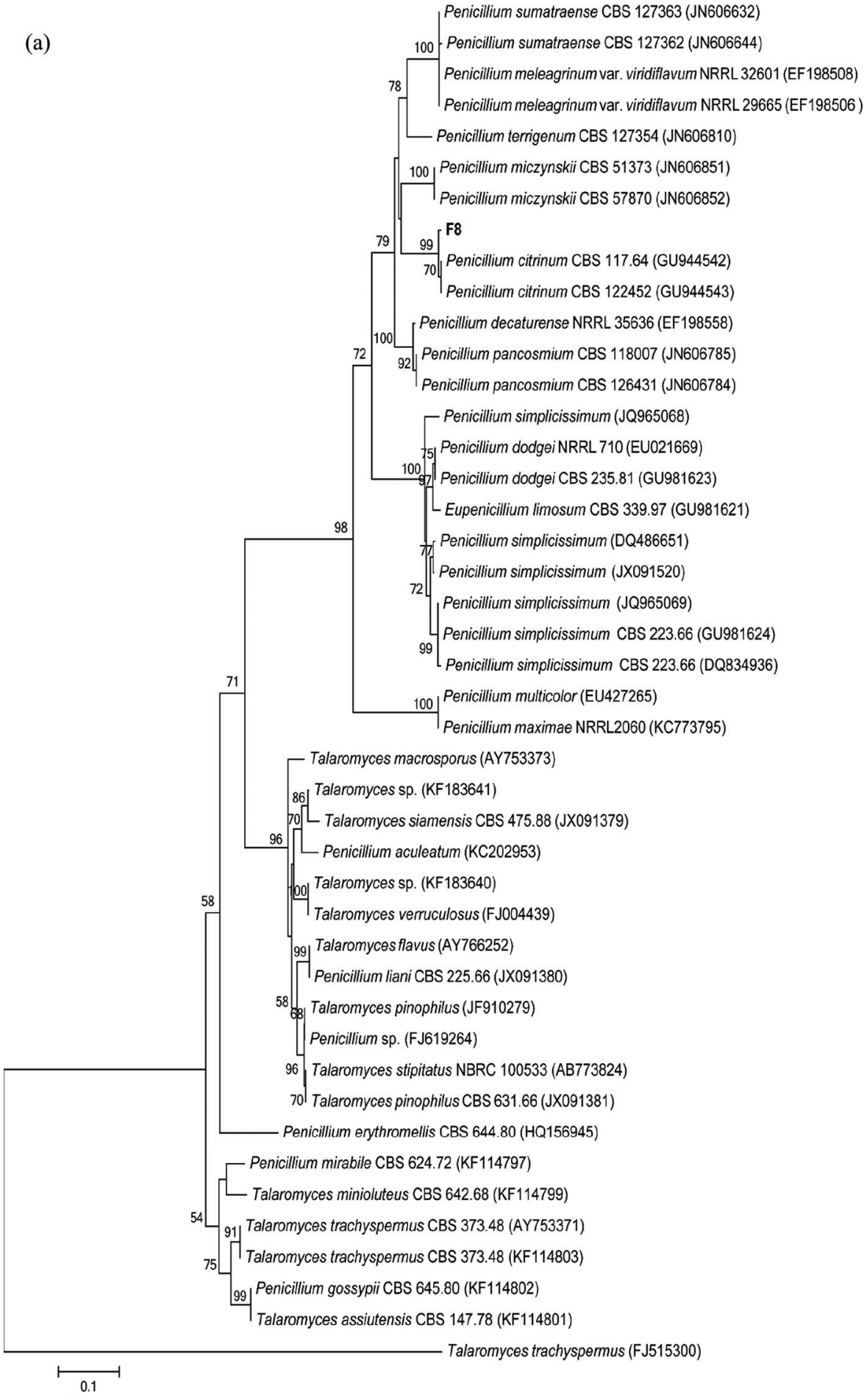

Figure 1. Neighbor-joining phylogenetic tree analysis based on $\beta$-tubulin sequences of Penicillium (a), Aspergillus (b), and allied species. The tree was inferred under the Kimura 2-parameters substitution model. Numbers on branches indicate bootstrap values from 1000 pseudo-replicates (values lower than $50 \%$ are not shown). The scale bar indicates 0.1 (a) and 0.01 (b) substitutions per site. All sequences were retrieved from GenBank (accessions are shown in parentheses). CBS (Centraalbureau voor Schimmelcultures Fungal Biodiversity Centre); NRRL (Agricultural Research Service Culture Collection) voucher accessions are also shown. ${ }^{\top}$ : type strain.

Hajji et al. ${ }^{[20]}$ on A spergillus clavatus ES1, Silva et al. ${ }^{[5]}$ on Aspergillus fumigatus; and Silva et al. ${ }^{[17]}$ on Penicillium waksmanii and Penicillium corylophilum.

The effect of temperature on enzyme activity was studied using the predetermined optimal $\mathrm{pH}$ for each enzymatic extract. The optimal temperature for peptidase activity in the crude enzyme extract of $P$. citrinum was $45^{\circ} \mathrm{C}$. This peptidase is sensitive to temperatures above $45^{\circ} \mathrm{C}$, as there is a notable
$40 \%$ decrease in enzymatic activity at $50^{\circ} \mathrm{C}$ and a total loss of activity at $55^{\circ} \mathrm{C}$ (Figure $3 \mathrm{~b}$ ).

For peptidases of the enzymatic extract from A. fischeri, we noted higher proteolytic activity at $55-60^{\circ} \mathrm{C}$, although there were no statistically significant differences between these temperatures $(p=0.09)$. We observed an intense loss of proteolytic activity above the optimal temperature, similar to that noted in the enzymatic extract from $P$. citrinum. Other 


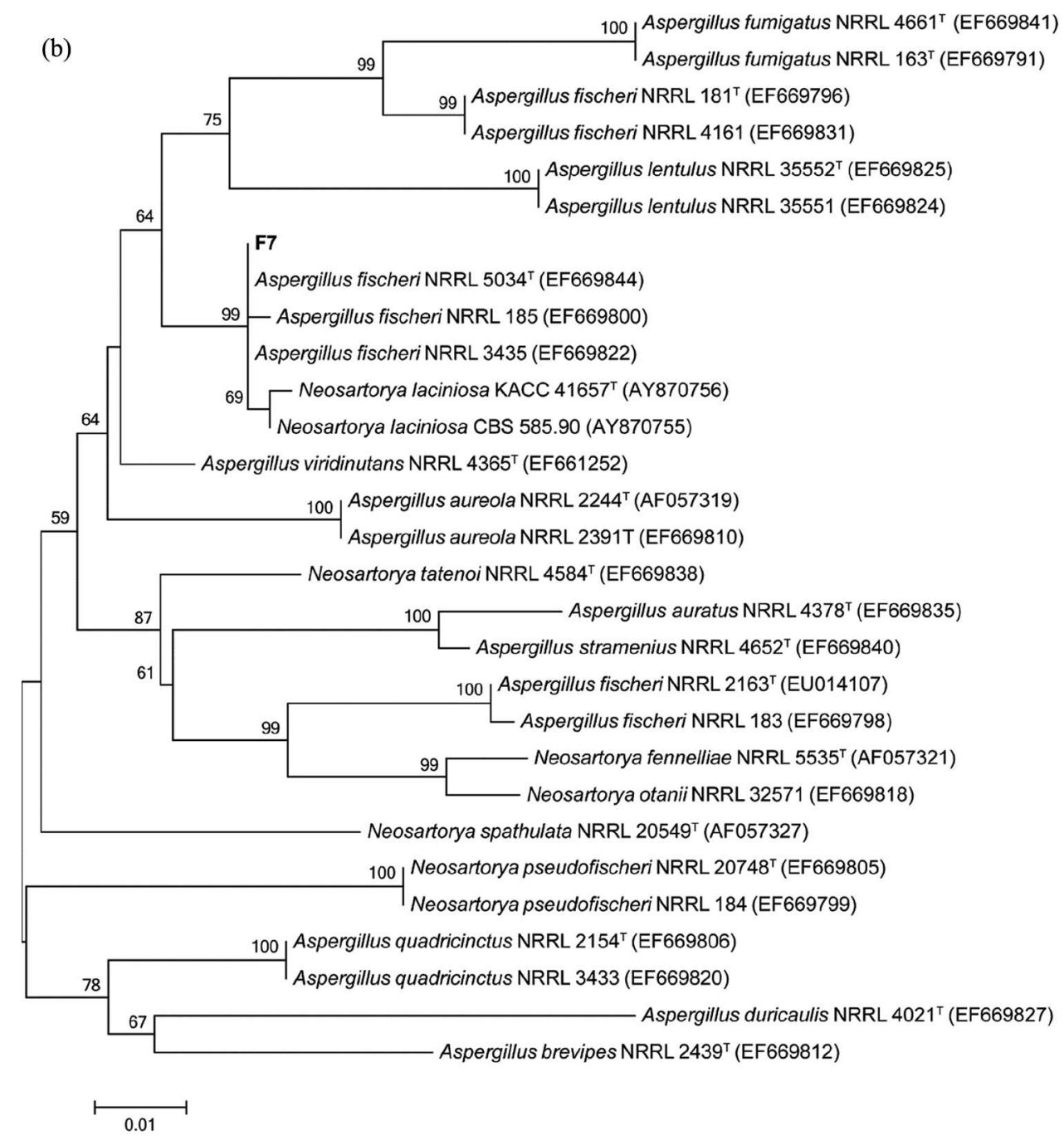

Figure 1. Continued.

researchers ${ }^{[20]}$ have reported similar results with peptidases exhibiting optimal temperatures of $45-55^{\circ} \mathrm{C}$.

In terms of stability, the peptidases secreted by both filamentous fungi remained stable over $\mathrm{pH} 4.5-10.5$, as shown in Figure 3c; a relative activity higher than $70 \%$ at all $\mathrm{pH}$ values was maintained by peptidase(s) from A. fischeri and an activity of approximately $90 \%$ was maintained by peptidase(s) from P. citrinum. Peptidases that can tolerate exposure to different $\mathrm{pH}$ ranges, especially alkaline conditions, are important as they have potential to be used as additives in detergents. The use of these enzymes in detergent formulations is required to remove protein stains on clothes or other dirty surfaces, and stability at alkaline $\mathrm{pH}$ is a fundamental and relevant biochemical property of these peptidases. Similar reports showing that fungal peptidases retain high stability over a wide $\mathrm{pH}$ range include those by Angelo et al. ${ }^{[21]}$ with Fusarium oxysporum, Silva et al. ${ }^{[5]}$ with $A$. fumigatus, and Silva et al. ${ }^{[17]}$ in serine peptidases secreted by $P$. corylophilum and P. waksmanii.

As shown in Figure 4a, we observed that peptidase secreted by $P$. citrinum remained stable over a temperature of $30-45^{\circ} \mathrm{C}$, maintaining a residual activity of $70 \%$ at $45^{\circ} \mathrm{C}$ for $60 \mathrm{~min}$ of incubation and approximately $50 \%$ of its enzymatic performance after $15 \mathrm{~min}$ at $50^{\circ} \mathrm{C}$.
Additionally, the peptidases of the crude enzyme extract of A. fischeri exhibited thermal stability in $30-50^{\circ} \mathrm{C}$, maintaining a residual activity of $80 \%$ for $60 \mathrm{~min}$ at $50^{\circ} \mathrm{C}$ and approximately $60 \%$ at $55^{\circ} \mathrm{C}$ when incubated for $30 \mathrm{~min}$ (Figure $4 \mathrm{~b}$ ). These results are similar to those reported by Wang et al. ${ }^{[22]}$ in A. fumigatus peptidases, in which a residual activity of approximately $90 \%$ after incubation at $50^{\circ} \mathrm{C}$ for $30 \mathrm{~min}$ was reported. The thermal stability of peptidases from A. fischeri is superior to those demonstrated by serine peptidases from A. fumigatus ${ }^{[23]}$ and A. clavatus ES $1 .{ }^{[20]}$

In comparison, the peptidases secreted by $A$. fischeri demonstrated greater thermal stability than those from P. citrinum, as the former showed activity and stability at higher temperatures.

\section{Effect of inhibitors and metal ions on peptidase activity}

In this study, proteolytic assays were performed in the presence of enzyme inhibitors (PMSF, IAA, and EDTA) and metal ions.

For crude enzymatic extracts from $P$. citrinum and $A$. fischeri, considerable inhibition of proteolytic activity was observed in incubation with PMSF. In the presence of this inhibitor (final concentration, $5 \mathrm{mM}$ ), the enzymatic activity 

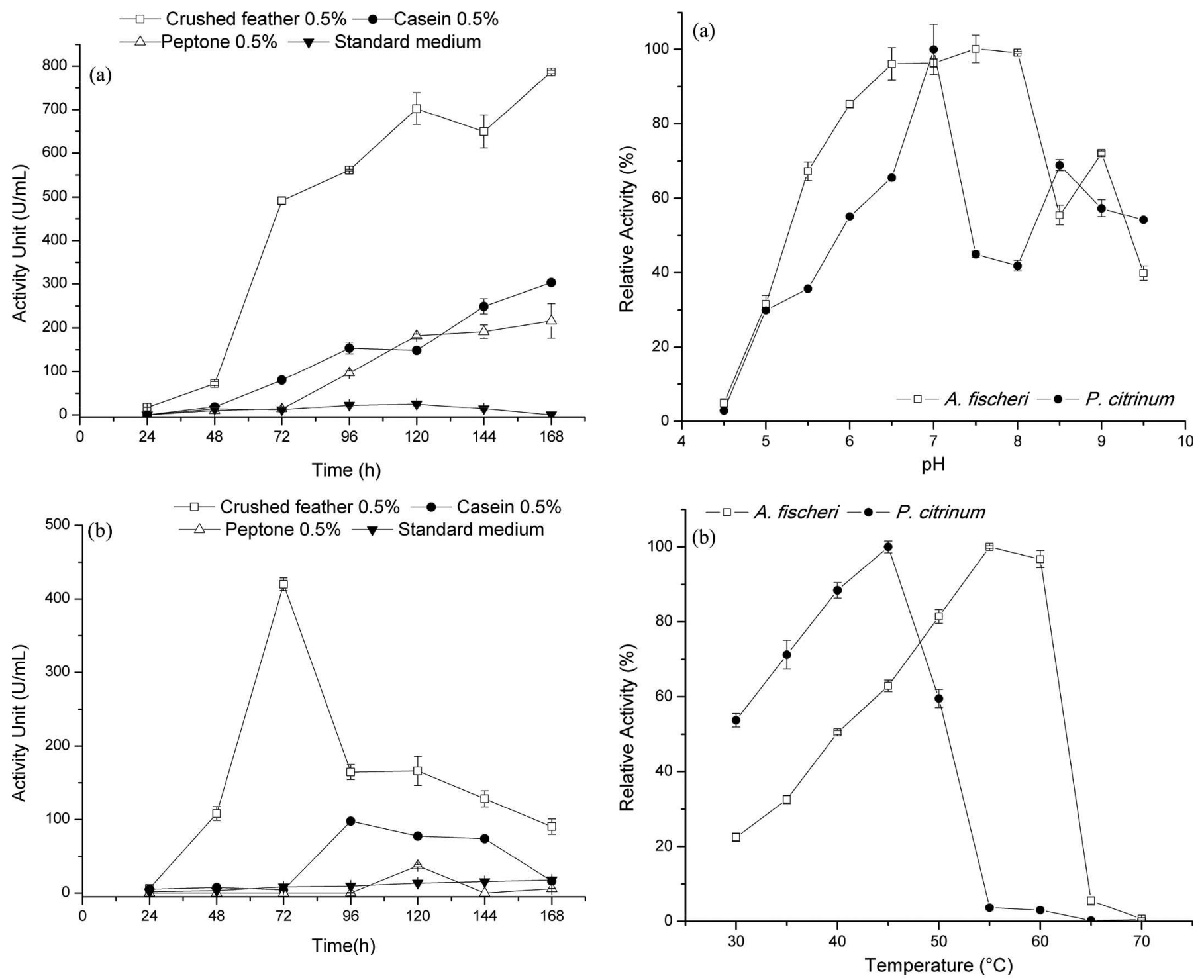

Figure 2. Profile of peptidase production by $P$. citrinum (a) and A. fischeri (b). $\mathrm{SmB}$ was performed at $120 \mathrm{rpm}$ and $30^{\circ} \mathrm{C}$.

of peptidases from P. citrinum and A. fischeri was reduced to 2 and $3 \%$, respectively. This reduction to a value close to zero suggests the presence of serine peptidases in the crude extracts of these fungi. The production of serine peptidases in bioprocesses using fungi has also been reported by other researchers. ${ }^{[5,22]}$

The effect of the metal ions $\mathrm{Li}^{+}, \mathrm{Na}^{+}, \mathrm{K}^{+}, \mathrm{Ba}^{2+}, \mathrm{Ca}^{2+}$, $\mathrm{Mg}^{2+}, \mathrm{Mn}^{2+}, \mathrm{Ni}^{2+}, \mathrm{Cu}^{2+}, \mathrm{Co}^{2+}, \mathrm{Al}^{3+}$, and $\mathrm{Zn}^{2+}$ on peptidase activity was studied. According to the data shown in Table 1, positive modulation in enzymatic activity was detected when the peptidases from $P$. citrinum were incubated in the presence of $\mathrm{Mn}^{2+}(31 \%), \mathrm{Ba}^{2+}(24 \%), \mathrm{Ca}^{2+}(22 \%), \mathrm{Al}^{3+}(21 \%), \mathrm{Na}^{+}$ (20\%), $\mathrm{Li}^{+}(18 \%), \mathrm{Mg}^{2+}(16 \%), \mathrm{K}^{+}(16 \%)$; the differences were statistically significant in all cases $(p=0.0001)$. Negative modulation was seen with the addition of $\mathrm{Zn}^{2+}, \mathrm{Co}^{2+}$, and $\mathrm{Ni}^{2+}$, and especially with $\mathrm{Cu}^{2+}$, which resulted in a residual activity of $47 \%$.

A similar profile of modulation for proteolytic performance was displayed by peptidases from A. fischeri. As shown in Table 1, we observed a slight positive modulation in activity after incubation with $\mathrm{Ba}^{2+}, \mathrm{Ca}^{2+}, \mathrm{Mg}^{2+}$, and $\mathrm{Na}^{+}$; statistically

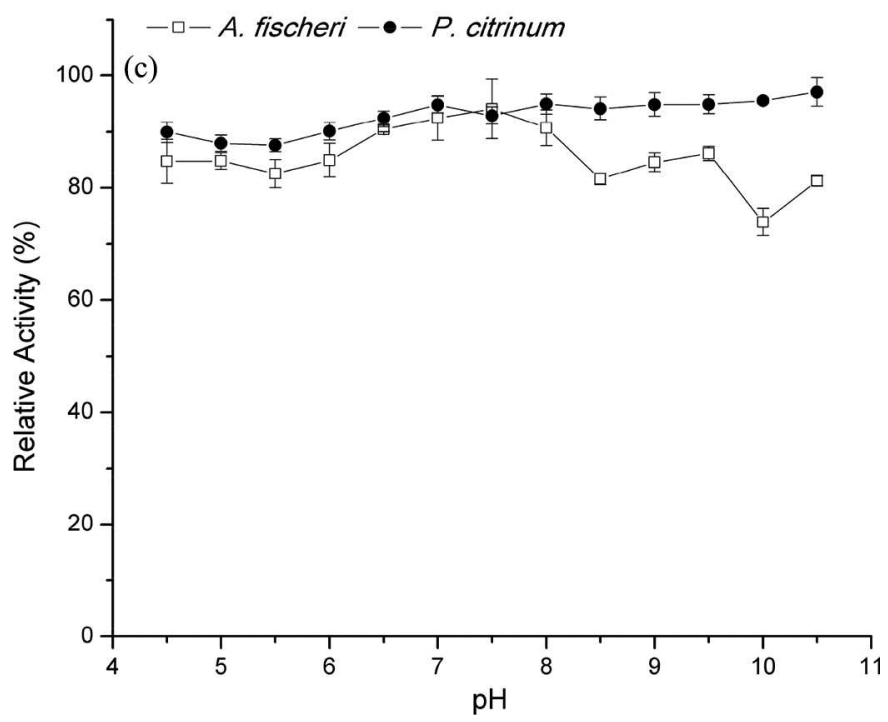

Figure 3. Effect of $\mathrm{pH}$ (a) and temperature (b) on proteolytic activity, and pH stability (c) of the crude enzyme extract of $P$. citrinum and $A$. fischeri.

significant differences were seen with $\mathrm{Li}^{+}(p=0.002)$ and $\mathrm{Mn}^{2+}(p=0.053)$. Additionally, reduction in enzymatic activity was noted in the presence of $\mathrm{Ni}^{2+}$ and $\mathrm{Zn}^{2+}$, and 



Figure 4. Effect of temperature on stability of the peptidases secreted by $P$. citrinum (a) and A. fischeri (b).

especially with $\mathrm{Cu}^{2+}$, wherein a notable residual activity of $36 \%$ was detected.

Metallic ions can promote chemical bonding with a side chain of the protein or active site of the enzyme and consequently influence enzymatic catalysis. In the active site of these peptidases, serine residues are crucial reactive components

Table 1. Effect of metallic ions on peptidase activity from P. citrinum and A. fischeri.

\begin{tabular}{lccc}
\hline & Relative activity (\%) & & Relative activity (\%) \\
\cline { 2 - 2 } Metallic ions (5 mM) & Peptidase from P. citrinum & & Peptidase from A. fischeri \\
\hline None & $100.0 \pm 4.7$ & & $100.0 \pm 2.0$ \\
$\mathrm{Al}^{3+}$ & $122.0 \pm 7.0$ & & $91.0 \pm 2.5$ \\
$\mathrm{Ba}^{2+}$ & $124.0 \pm 0.8$ & & $118.0 \pm 3.0$ \\
$\mathrm{Ca}^{2+}$ & $121.0 \pm 2.0$ & & $116.0 \pm 4.0$ \\
$\mathrm{Co}^{2+}$ & $82.0 \pm 8.0$ & & $77.0 \pm 2.0$ \\
$\mathrm{Cu}^{2+}$ & $47.0 \pm 0.5$ & & $36.0 \pm 0.5$ \\
$\mathrm{~K}^{+}$ & $116.0 \pm 3.5$ & & $99.0 \pm 2.5$ \\
$\mathrm{Li}^{+}$ & $118.0 \pm 5.0$ & & $108.0 \pm 2.0$ \\
$\mathrm{Mg}^{2+}$ & $116.0 \pm 2.5$ & & $113.0 \pm 4.0$ \\
$\mathrm{Mn}^{2+}$ & $131.0 \pm 3.0$ & & $104.0 \pm 4.0$ \\
$\mathrm{Na}^{+}$ & $120.0 \pm 2.0$ & & $111.0 \pm 3.0$ \\
$\mathrm{Ni}^{2+}$ & $76.0 \pm 1.0$ & & $63.0 \pm 1.5$ \\
$\mathrm{Zn}^{2+}$ & $88.0 \pm 2.0$ & & $52.0 \pm 1.0$ \\
\hline
\end{tabular}

Values are the average of three independent experiments \pm standard deviations. that can interact chemically with metallic ions and promote considerable reductions in enzymatic catalysis. In studies on fungal serine peptidases, Da Silva et al. ${ }^{[24]}$ showed slight improvement in proteolysis in the presence of potassium, and Hajji et al. ${ }^{[20]}$ described positive modulation in activity by magnesium and calcium and negative modulation by zinc and copper II. Graminho et al. ${ }^{[25]}$ also reported increases in the activity of a serine peptidase from $P$. waksmanii in the presence of calcium, barium, and potassium ions.

Additionally, in studies with crude extract, it is necessary to point out that a slight or insignificant change on enzymatic activity can be derived from nonspecific binding of metal ion with protein.

\section{Effect of surfactants, collagenase activity, and washing performance in commercial detergent}

Using ionic (SDS and CTAB) and nonionic (Tween 20 and Triton X-100) surfactants, we performed a study to determine the influence of these chemical agents on the denaturation of the fungal peptidases.

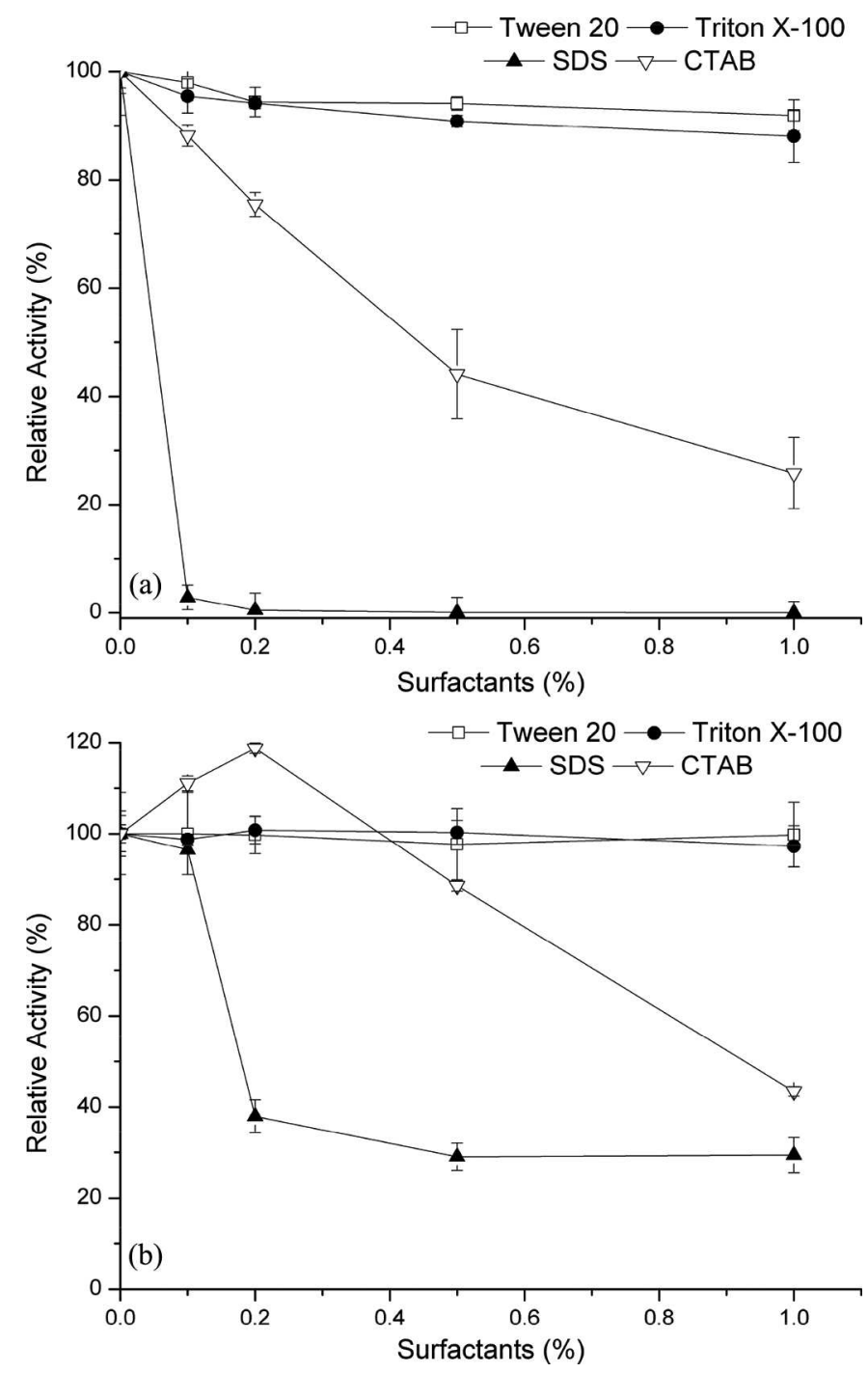

Figure 5. Effect of surfactants on peptidase activity from P. citrinum (a) and A. fischeri (b). 


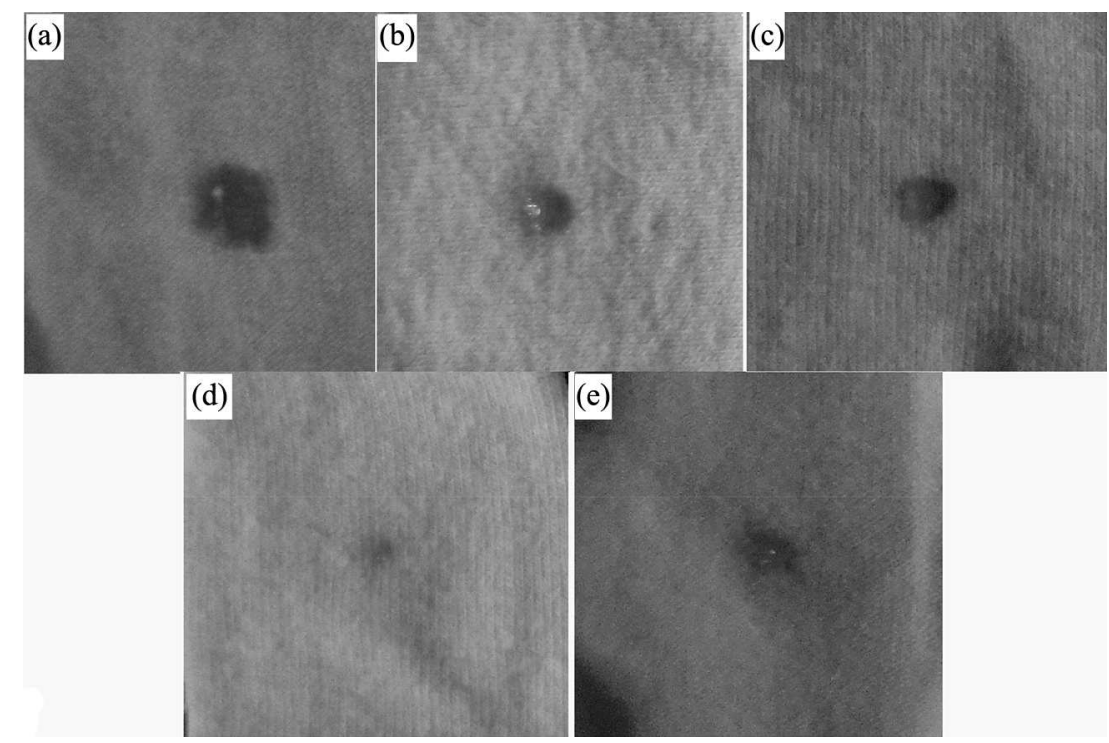

Figure 6. Washing performance with water (a), with commercial detergent without proteolytic activity (thermally denatured enzyme) (b), with active commercial detergent (c), with commercial detergent (denatured enzyme) plus peptidase from P. citrinum (d), and with commercial detergent (denatured enzyme) plus peptidase from A. fischeri (e).

The data displayed in Figure $5 \mathrm{a}$ and $\mathrm{b}$ show that the presence of nonionic surfactants did not interfere with enzymatic activity, as enzymatic activity was maintained by peptidases from both extracts. However, when peptidases were incubated with ionic surfactants, considerable negative modulation in enzymatic catalysis was noted.

The highest reduction in proteolysis for both fungal peptidase extracts was observed in the presence of $0.2 \%$ SDS, as a total loss of catalysis was seen for peptidases from P. citrinum (Figure 5a) and a residual activity of approximately $40 \%$ was seen for peptidases from A. fischeri (Figure $5 b$ ). Residual activity of $45 \%$ for peptidases from $P$. citrinum and $88 \%$ for peptidases from A. fischeri was observed in the presence of $0.5 \%$ CTAB. Additionally, at $1 \% \mathrm{CTAB}$, we observed $25 \%$ residual activity in peptidases from $P$. citrinum and $45 \%$ in peptidases secreted by A. fischeri. Interestingly, an increase in the enzymatic activity of peptidases secreted by $A$. fischeri was seen with CTAB at concentrations of $0.1-0.2 \%$, demonstrating a possible improvement in the molecular arrangement of these peptidases or an effect on the substrate that favors access of the enzyme to the substrate azocasein.

We noted more interference in the presence of ionic surfactants (CTAB and SDS) than that with nonionic surfactants (Tween 20 and Triton X-100); thus, hydrophobic forces are critical to protein arrangement, and surfactants (especially SDS) particularly influence the denaturation of the enzymes. Intense decreases in proteolytic activity in response to surfactants have also been reported by other studies, especially those involving SDS, in fungal serine peptidases from Penicillium species $^{[17,25]}$ and Aspergillus species. ${ }^{[24]}$

To check the capacity of the crude enzymatic extract for collagenolytic hydrolysis, we performed a proteolytic assay using an Azocoll substrate. The results showed that crude enzymatic extracts from $P$. citrinum and A. fischeri both had collagenolytic activity, with 126 A.U. for the enzymatic extract isolated from $P$. citrinum and 116 A.U. for those from
A. fischeri. Fungal collagenolytic peptidase production has also been described by other researchers. ${ }^{[26,27]}$ Collagenolytic activity of peptidases is an important characteristic for a variety of industrial applications of these enzymes, including notable uses in leather processing, in moisturizers for cosmetics, and in medicine to treat burns and ulcers. ${ }^{[3,26,28]}$

We evaluated the washing performance of water, a commercial detergent without proteolytic activity (thermal denaturation), and an active commercial detergent to remove an egg protein stain (Figure 6). The results show that all three solutions were not active in removing the egg stain (Figure 6a-c).

However, we observed that the detergent supplemented with peptidases from $P$. citrinum exhibited a notably higher capacity to remove egg stain compared to that seen on using active detergent; the supplemented detergent promoted slight cleaning of the fabric (Figure 6d). These results provide important information about these enzymes and their potential applications and suggest that washing performance can be optimized with appropriate conditions of enzyme concentration, time, and heating during the washing process to maintain enzymatic stability. It is worth noting that the production and application processes performed in this study were with relatively simple methods, involved low production cost, and used a crude enzyme extract. Haddar et al. ${ }^{[29]}$ and Jellouli et al. ${ }^{[30]}$ reported similar washing performance using microbial enzymes to remove blood stains. Abidi et al. ${ }^{[4]}$ also showed the effective removal of an egg stain by washing with a commercial detergent supplemented with a fungal peptidase.

\section{Conclusion}

We observed that, in $\mathrm{SmB}$, the fungus $P$. citrinum was a better producer of peptidases than A. fischeri. We also demonstrate the great potential of an animal residue, crushed feathers, for use as an optimal inducer of peptidase production in this 
fermentation process. We intend to use the information obtained from the studies on biochemical characterization, collagen hydrolysis capacity, and compatibility with commercial detergents to improve the washing performance and the application perspectives of these enzymes in future studies.

\section{Funding}

The authors would like to acknowledge the financial support provided by Fundação de Amparo à Pesquisa do Estado de São Paulo-FAPESP, (process 2011/06986-0 and 2012/24703-8) Conselho Nacional de Desenvolvimento Científico e Tecnológico and Instituto Nacional de Ciência e Tecnologia-Rede de Biotecnologia Farmacêutica.

\section{References}

[1] El-Enshasy, H.A. Filamentous Fungal Cultures-process Characteristics, Products, and Applications. In Bioprocessing for Value-Added Products from Renewable Resources. Shang-Tian, Y., Ed.; Elsevier, Amsterdam, 2007; pp. 225-262.

[2] Sandhya, C.; Sumantha, A.; Szakacs, G.; Pandey, A. Comparative Evaluation of Neutral Protease Production by Aspergillus oryzae in Submerged and Solid-state Fermentation. Process Biochem. 2005, 40, 2689-2694.

[3] Rao, M.B.; Tanksale, A.M.; Ghatge, M.S.; Deshpande, V.V. Molecular and Biotechnological Aspects of Microbial Proteases. Microbiol. Mol. Biol. Rev. 1998, 62, 597-635.

[4] Abidi, F.; Limam, F.; Nejib, M.M. Production of Alkaline Proteases by Botrytis cinerea using Economic Raw Materials: Assay Biodetergent. Process Biochem. 2008, 43, 1202-1208.

[5] Silva, R.R.; Cabral, T.P.F.; Rodrigues, A.; Cabral, H. Production and Partial Characterization of Serine and Metallo Peptidases Secreted by Aspergillus fumigatus Fresenius in Submerged and Solid State Fermentation. Braz. J. Microbiol. 2013, 44, 235-243.

[6] Arcuri, S.L.; Pagnocca, F.C.; Melo, W.G.P.; Nagamoto, N.S.; Komura, D.L.; Rodrigues, A. Yeasts Found on an Ephemeral Reproductive Caste of the Leaf-cutting ant Atta sexdens rubropilosa. Ant. Van. Leeuw. 2014. doi:10.1007/s10482-014-0216-2

[7] Glass, N.L.; Donaldson, G. Development of Primer Sets Designed for Use with the PCR to Amplify Conserved Genes from Filamentous Ascomycetes. Appl. Environ. Microbiol. 1995, 61, 1323-1330.

[8] Hall, T.A. BioEdit: A User-friendly Biological Sequence Alignment Editor and Analysis Program for Windows 95/98/NT. Nucleic Acids Symp. Ser. 1999, 41, 95-98.

[9] Katoh, K.; Standley, D.M. MAFFT Multiple Sequence Alignment Software Version 7: Improvements in Performance and Usability. Mol. Biol. Evol. 2013, 30, 772-780.

[10] Tamura, K.; Peterson, D.; Peterson, N.; Stecher, G.; Nei, M.; Kumar, S. MEGA5: Molecular Evolutionary Genetics Analysis using Maximum Likelihood, Evolutionary Distance, and Maximum Parsimony Methods. Mol. Biol. Evol. 2011, 28, 2731-2739. doi:10.1093/ molbev/msr121.

[11] Tran, L.H.; Nagano, H. Isolation and characteristics of Bacillus subtilis $\mathrm{CN} 2$ and its colagenase production. J. Food. Sci. 2002, 67, 1184-1187.

[12] Sarath, G.; de la Motte, R.S.; Wagner, F.W. Protease Assay Methods. In Proteolytic Enzymes: A Practical Approach. Beynon, R.J.; Bond, J.S. Eds.; IRL Press, NY, 1996; pp. 25-55.

[13] Meyers, S.P.; Ahearn, D.G. Extracellular Proteolysis by Candida lipolytica. Mycologia. 1977, 69, 646-651.

[14] Ducros, E.; Ferrari, M.; Pellegrino, M.; Raspanti, C.; Bogni, C. Effect of Aeration and Agitation on the Protease Production by
Staphylococcus aureus Mutant RC128 in a Stirred Tank Bioreactor. Bioprocess Biosyst. Eng. 2009, 32, 143-148.

[15] Mukherjee, J.; Webster, N.; Llewellyn, L.E. Purification and Characterization of a Collagenolytic Enzyme from a Pathogen of the Great Barrier Reef Sponge. Rhopaloeides odorabile. PLoS ONE. 2009, 4, e7177. doi:10.1371/journal.pone.0007177

[16] Voltan, A.R.; Donofrio, F.; Miranda, E.T.; Moraes, R.A.; Mendes-Giannini, M.J.S. Induction and Secretion of Elastinolytic and Proteolytic Activity in Cultures Of Paracoccidioides brasiliensis. Rev. Ciênc. Farm. Básica Apl. 2008, 29, 97-106.

[17] Silva, R.R.; Angelo, T.; Cabral, H. Comparative Evaluation of Peptidases Produced by Penicillium corylophilum and Penicillium waksmanii in Solid State Fermentation using Agro-industrial Residues. J. Agri. Sci. Technol. B. 2013, 3, 230-237.

[18] Pandey, A. Solid-state Fermentation. Biochem. Eng. J. 2003, 13, 8184.

[19] Tunga, R.; Shrivastava, B.; Banerjee, R. Purification and Characterization of a Protease from Solid State Culture of Aspergillus parasiticus. Process Biochem. 2003, 38, 1553-1558.

[20] Hajji, M.; Rebai, A.; Gharsallah, N.; Nasri, M. Optimization of Alkaline Protease Production by Aspergillus clavatus ES1 in Mirabilis jalapa Tuber Powder using Statistical Experimental Design. Appl. Microbiol. Biotechnol. 2008, 79, 915-923.

[21] Angelo, T.; Silva, R.R.; Cabral, H. Concomitant Production of Peptidases and Lipases by Fungus Using Agroindustrial Residue in Solid-state Fermentation. Int. J. Curr. Microbiol. App. Sci. 2014, $5,810-823$.

[22] Wang, S.-L.; Chen, Y.-H.; Wang, C.-L.; Yen, Y.-H.; Chern, M.-K. Purification and Characterization of a Serine Peptidase Extracellularly Produced by Aspergillus fumigatus in a Shrimp and Crab Shell Powder Medium. Enzyme Microb. Technol. 2005, 36, 660-665.

[23] Larcher, G.; Bouchara, J.P.; Annaix, V.; Symoens, F.; Chabasse, D.; Tronchin, G. Purification and Characterization of a fibrinogenolytic serine proteinase from Aspergillus fumigatus culture filtrate. FEBS Lett. 1992, 308, 65-69.

[24] Da Silva, R.R.; Caetano, R.C.; Okamoto, D.N.; de Oliveira, L.C.G.; Bertolin, T.C.; Juliano, M.A.; Juliano, L.; Oliveira, A.H.C.; Rosa, J.C.; Cabral, H. The Identification and Biochemical Properties of the Catalytic Specificity of a Serine Peptidase Secreted by Aspergillus fumigatus Fresenius. Protein Pept. Lett. 2014, 21, 663-671.

[25] Graminho, E.R.; Silva, R.R.; Cabral, T.P.F.; Arantes, E.C.; da Rosa, N.G.; Juliano, L.; Okamoto, D.N.; Oliveira, L.C.G.; Kondo, M.Y.; Juliano, M.A.; Cabral, H. Purification, Characterization, and Specificity Determination of a New Serine Protease Secreted by Penicillium waksmanii. Appl. Biochem. Biotechnol. 2013, 169, 201-214.

[26] Lima, C.A.; Rodrigues, P.M.B.; Porto, T.S.; Viana, D.A.; Filho, J.L.L.; Porto, A.L.F.; Cunha, M.G.C. Production of a Collagenase from Candida albicans URM3622. Biochem. Eng. J. 2009, 43, 315-320.

[27] Datta, A. Purification and Characterization of a Novel Protease from Solid Substrate Cultures of Phanerochaete chrysosporium. J. Biol. Chem. 1992, 267, 728-732.

[28] Daboor, S.M.; Budge, S.M.; Ghaly, A.E.; Brooks, S.-L.; Dave, D. Extraction and Purification of Collagenase Enzymes: A Critical Review. Am. J. Biochem. Biotech. 2010, 6, 239-263.

[29] Haddar, A.; Hmidet, N.; Ghorbel-Bellaaj, O.; Fakhfakh-Zouari, N.; Sellami-Kamoun, A.; Nasri, M. Alkaline Proteases Produced by Bacillus licheniformis RP1 Grown on Shrimp Wastes: Application in Chitin Extraction, Chicken Feather Degradation and as a Dehairing Agent. Biotechnol. Bioproc. Eng. 2011, 16, 669-678.

[30] Jellouli, K.; Ghorbel-Bellaaj, O.; Ayed, HB.; Manni, L.; Agrebi, R.; Nasri, M. Alkaline-protease from Bacillus licheniformis MP1: Purification, Characterization and Potential Application as a Detergent Additive and for Shrimp Waste Deproteinization. Process Biochem. 2011, 46, 1248-1256. 